\title{
Direct mass analysis of water absorption onto ceria thin films
}

\author{
D. Laventine, ${ }^{1}$ C. Boxall, ${ }^{1 *}$ R. Taylor, ${ }^{2}$ and R. Orr. ${ }^{2}$ \\ ${ }^{1}$ University of Lancaster, Department of Engineering, Lancaster, LA1 4YR, UK \\ ${ }^{2}$ National Nuclear Laboratory, Central laboratory, B170, Sellafield, CA20 1PG, UK
}

\begin{abstract}
Plutonium oxide $\left(\mathrm{PuO}_{2}\right)$ is one of the most highly radioactive components of nuclear fuel waste streams and its storage poses particular challenges due to the high temperatures produced by its decay and the production of gases (particularly $\mathrm{H}_{2}$ and steam). Its high radiotoxicity necessitates the use of analogues, such as $\mathrm{CeO}_{2}$, to allow the comprehensive study of its interaction with water under storage conditions.

We have developed a method which enables direct gravimetric measurement of water adsorption onto $\mathrm{CeO}_{2}$ thin films with masses in the microgram region. Porous $\mathrm{CeO}_{2}$ films were fabricated from a surfactant based precursor solution. The absorption of water onto the $\mathrm{CeO}_{2}$ coating at different relative humidities was studied in a closed reactor. Quartz Crystal Microbalance (QCM) gravimetry was used as a signal transducer, as changes in crystal resonant frequency due to absorbed mass are directly and linearly related to mass changes occurring at the crystal surface. Using this method, we have determined the enthalpy of absorption of water onto $\mathrm{CeO}_{2}$ to be $50.7 \mathrm{kJmol}^{-1}$ at $75^{\circ} \mathrm{C}, 12 \mathrm{kJmol}^{-1}$ greater than the enthalpy of evaporation. This enthalpy is within the range predicted for the absorption of water onto $\mathrm{PuO}_{2}$, indicating this method allows for investigation of water absorption using microgram samples.
\end{abstract}

\section{INTRODUCTION}

Plutonium oxide $\left(\mathrm{PuO}_{2}\right)$ is one of the most highly radioactive components of nuclear fuel waste streams. This poses particular challenges in storing large amounts for reuse as mixed oxide fuel for the next generation of fast reactors or for eventual deposition into long-term geological storage, which has been proposed at a number of sites worldwide. Interim storage is typically within a series of nested steel canisters under a partially inert atmosphere. These canisters develop high internal temperatures due to the $\mathrm{PuO}_{2}$ decay heat and have been observed to become pressurised due to the evolution of hydrogen gas and steam. A greater understanding of $\mathrm{PuO}_{2}$ interaction with water is therefore imperative to allow the design of safe long-term storage facilities.[1-3].

Ceria $\left(\mathrm{CeO}_{2}\right)$ is widely employed as a model substrate for radioactive metal oxides such as plutonium oxide, due to the metals similar ionic radii and the oxides similar fluorite structure.[4] Ceria polycrystals exhibit a significant absorption of water vapour at high temperatures $[5,6]$, and previous studies have indicated this to be true of plutonium oxide. The absorption of water results in numerous physio- and chemi-absorbed layers, but the subsequent fate of this water under elevated temperatures and pressures and in the presence of highly radioactive material is unknown. Water adsorption on $\mathrm{PuO}_{2}$ has previously been investigated by measuring headspace pressure, as a function of temperature within a closed system containing a fixed quantity of $\mathrm{PuO}_{2}$ in the presence of varying amounts of deliberately added water [7, 8]. 
This involves making a number of assumptions relating to the PVT behaviour of the headspace of the closed system, usually based on the behaviour of an ideal gas, in order to estimate the mass of water adsorbed at the $\mathrm{PuO}_{2}$ surface.[9, 10]

We have developed a method which enables direct gravimetric measurement of water adsorption onto $\mathrm{CeO}_{2}$ thin films. We have previously reported the use of Quartz Crystal Microbalance (QCM) gravimetry as a signal transducer,[11] as changes in crystal resonant frequency are directly related to mass changes occurring at the crystal surface at ambient temperatures[13]. In this work, ortho-gallium phosphate $\left(o-\mathrm{GaPO}_{4}\right)$ crystals were used instead of quartz due to the linear dependence of their resonant frequency on as well as their higher piezoelectric limiting temperature,[8] allowing the absorption of water to be analysed under the high temperature conditions that develop in typical $\mathrm{PuO}_{2}$ storage conditions. Herein, we describe preliminary experiments in the coating of $o-\mathrm{GaPO}_{4}$ crystal electrodes with nano-scale crystalline $\mathrm{CeO}_{2}$ films and measurements of their absorption of water.

\section{EXPERIMENT}

\section{Materials and Reagents}

All reagents used are AnalaR grade or higher, and purchased from Sigma Aldrich (Gillingham, Dorset, UK). All water used is Ultrapure doubly de-ionised water from a Direct-Q 3 UV Millipore water purification system (Millipore (U.K.) Limited, Watford, UK) to a

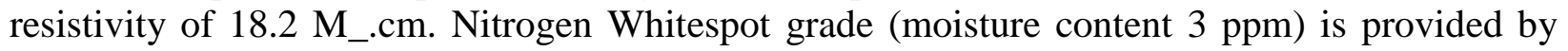
BOC Ltd., Guildford, Surrey, UK. All $o-\mathrm{GaPO}_{4}$ crystals used were $6 \mathrm{MHz}$ with platinum electrodes and a piezoelectrically active area of $0.342 \mathrm{~cm}^{2}$, purchased from Piezocyst GmbH, Austria. The heater, vessel and controller were purchased from Scientific and Medical Products, Cheadle, UK and had a system accuracy of $\pm 1^{\circ} \mathrm{C}$.

\section{Methods}

A $\mathrm{CeO}_{2}$ film was deposited on $o-\mathrm{GaPO}_{4}$ crystals using an adapted version of the Lundberg method for generating thin films of crystalline $\mathrm{CeO}_{2}$ [11]. A stock solution of 0.01 moles of $\mathrm{CeNO}_{3}$ and $5 \%$ of triton-X (a non-ionic polxamer surfactant) dissolved in $10 \mathrm{~mL}$ of 1:1 water-methanol was created. A second solution was produced by 10 -fold dilution of the stock solution. $10 \mu \mathrm{l}$ of the diluted solutions were drop-coated onto one electrode surface of $o-\mathrm{GaPO}_{4}$ crystal and allowed to evaporate in air, then calcined in air at $650^{\circ} \mathrm{C}$ for $5 \mathrm{~h}$, resulting in formation of an iridescent layers adhered to the platinum piezoelectrode surface.

The formation of crystalline $\mathrm{CeO}_{2}$ was confirmed by Raman spectroscopy and by XRD analysis of the layers. The morphology of the layers was investigated using a Phenom ${ }^{\mathrm{TM}}$ scanning electron microscope (Lambda Photometrics, Herfordshire). $\mathrm{CeO}_{2}$-coated crystal electrodes were mounted into commercially available crystal holders (Colnatec, US) constructed of steel and ceramic leaving only the coated crystal face accessible. The crystal mount is suspended within a steel reaction vessel ( $\mathrm{vol}=1 \mathrm{~L}$, fig. 1$)$ such that it is not in contact with any internal surface. A stream of dry nitrogen is passed into an inlet port on the reaction vessel and allowed to escape from an exhaust port while the vessel is heated in a furnace to $\sim 400^{\circ} \mathrm{C}$. This procedure is continued for $6+$ hours, or until the observed frequency of the crystal remains steady. The system is then sealed and allowed to return to RT and the baseline frequency 
recorded. A defined amount of water is added by microsyringe and the system is then re-sealed and the frequency and temperature recorded every second. As the water added to the system evaporated and redeposits onto the crystal surface, the frequency (inversely proportional to mass) is predicted to drop. Once a steady frequency is reached, the system is temperature cycled from RT to $\sim 350^{\circ} \mathrm{C}$ with continuous recording of the temperature and corresponding frequency. Once at RT again, the gas inlet is re-attached and a slow stream of nitrogen passed through the system until the frequency stabilises. The above procedure is then repeated (from the initial heat cycling) with a different amount of water added.

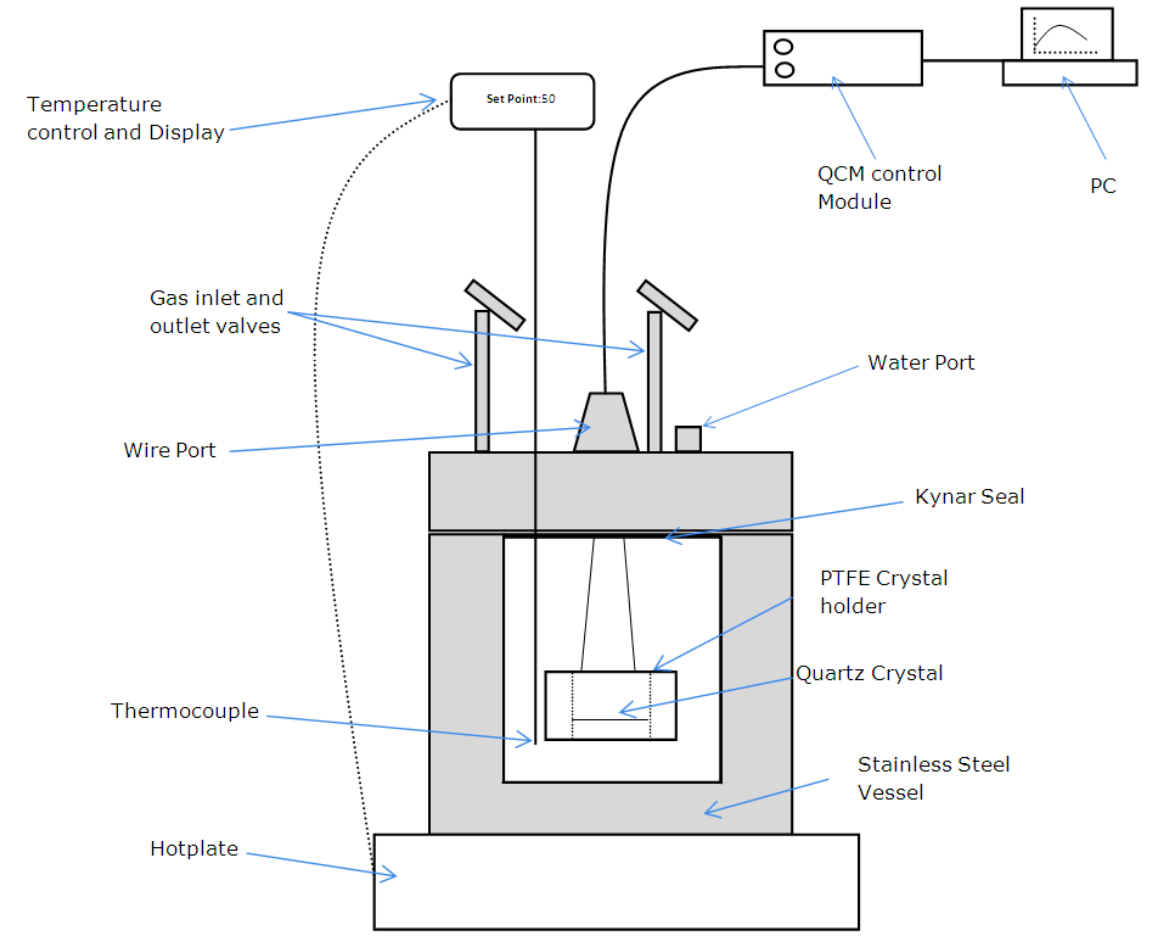

Figure 1. Schematic diagram of experimental setup.

\section{RESULTS \& DISCUSSION}

The layers formed by drop-coating and calcination were found to be strongly adhered to the platinum electrode surface, being resistant to manual abrasion. Raman spectroscopy (785 $\mathrm{nm}$ excitation) showed a characteristic $\mathrm{CeO}_{2}$ peak at $464 \mathrm{~nm}$ (fig. 2).[12] XRD measurements of a powder $\mathrm{CeO}_{2}$ sample produced under the same conditions as the crystal coatings indicted the samples were crystalline $\mathrm{CeO}_{2}$ (fig.3)[13].

Deposition of the $\mathrm{CeO}_{2}$ layers resulted in a resonant frequency drop of $7450 \mathrm{~Hz}$, equating to a $42 \mu \mathrm{g}$ increase in mass. This is below the $2 \%$ threshold at which the Sauerbrey equation becomes unreliable to describe mass changes occurring at the composite resonator surface. Using the area of the crystal electrode coated and the density of bulk ceria $\left(7.65 \mathrm{~g} / \mathrm{cm}^{-3}\right)$ [13], the layers were estimated to be $125 \mathrm{~nm}$ thick, assuming a homogenous non-porous coating with ideal geometry. 


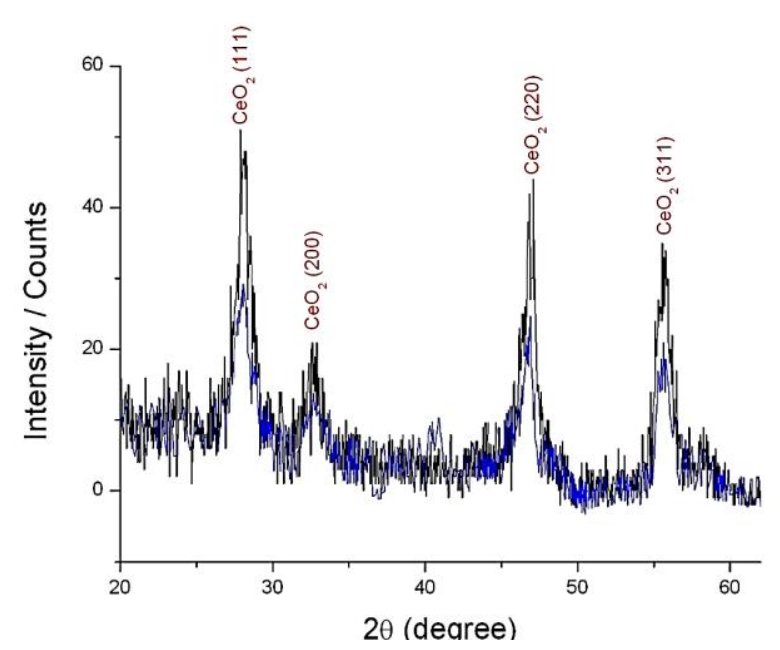

Figure 2. Figure 2. Powder XRD showing characteristic peaks for crystalline ceria, produced by evaporation calcination of the stock at $650^{\circ} \mathrm{C}$.

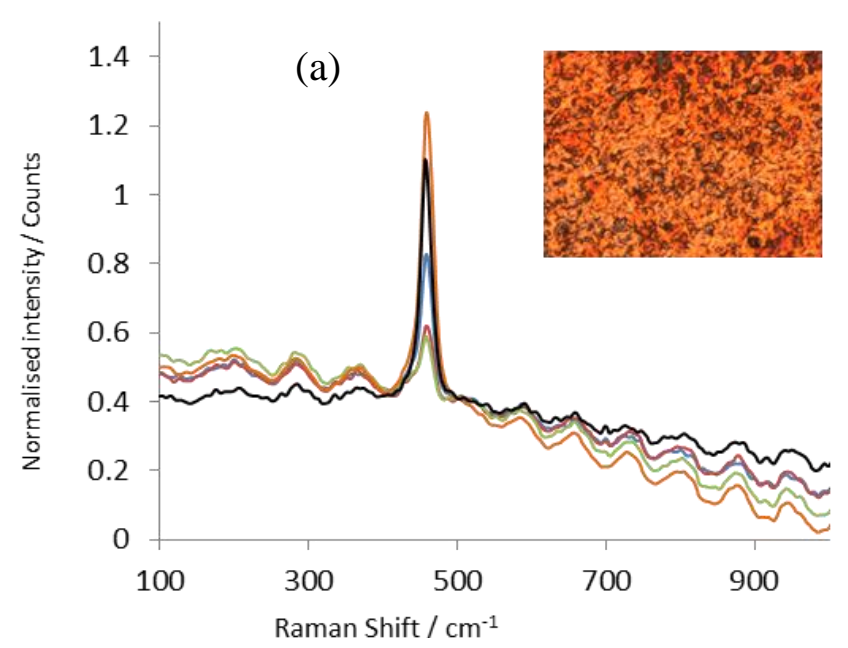

Figure 3. (a) Raman spectra of $\mathrm{CeO}_{2}$ layer measured at five points, with characteristic peak at $464 \mathrm{~cm}^{-1}$ (b) inset showing microscope image at 50 $\mathrm{x}$ magnification.

SEM imaging shows the layer to be comprised of a densely packed $\mathrm{CeO}_{2}$ network with voids and pores present (Figure 4). The thickness of the films was also measured by XRF in a 36 point grid, giving an average thickness of $261 \mathrm{~nm}, \pm 29 \mathrm{~nm}$ (figure 5). This gives a piezoactive volume of $8.9 \times 10^{-6} \mathrm{~cm}^{3}$ and therefore a porosity of $54 \%$.

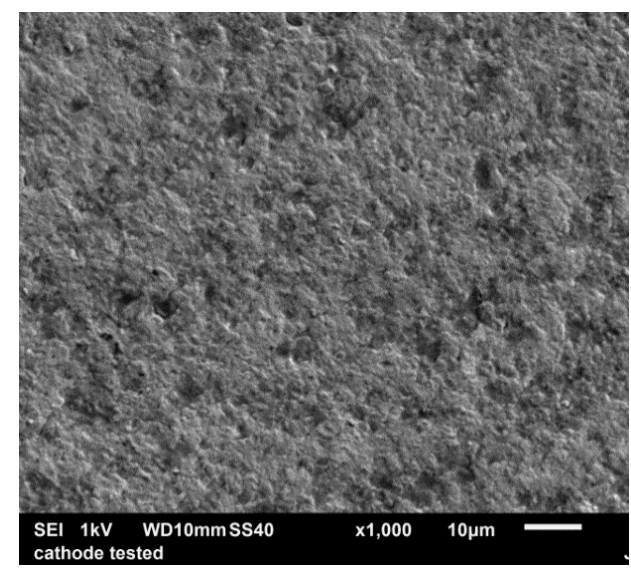

Figure 4. SEM image of a $\mathrm{CeO}_{2}$ film on a platinum / $o-\mathrm{GaPO}_{4}$ piezoelectrode.

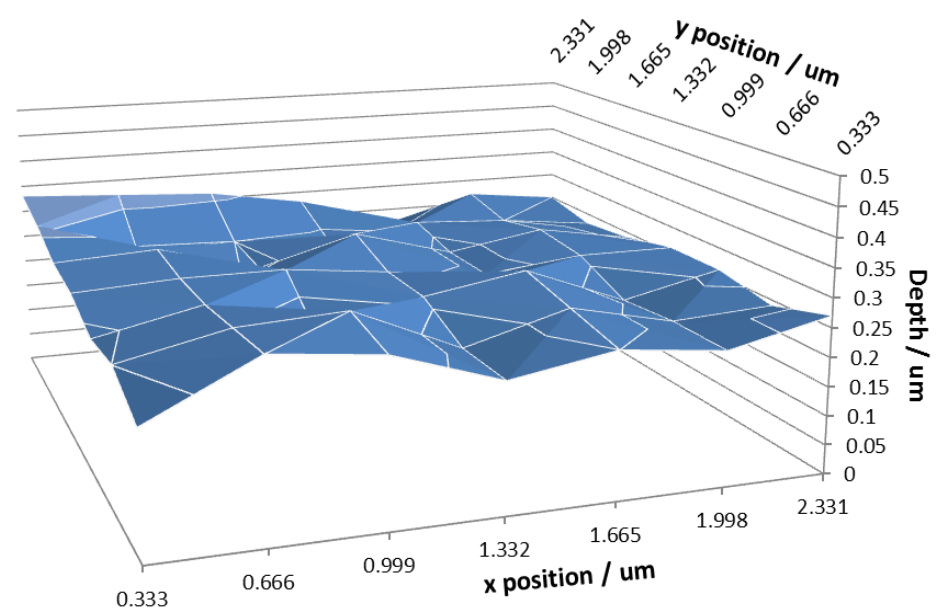

Figure 5. XRF map of $\mathrm{CeO}_{2}$ film thickness at 36 different points. Average thickness, $261 \mathrm{~nm}$.

Initial microbalance experiments with the coated crystals at were conducted at $75^{\circ} \mathrm{C}$. It was found that the resonant frequency of the coated crystals reduced in response to the addition of water to the system, corresponding to a $2.4 \mu \mathrm{g}$ mass increase per coated crystal (approximately $90 \mathrm{mg}$ of water absorbed per gram $\mathrm{CeO}_{2}$ layer) at $100 \%$ relative humidity. The relative humidity was varied by changing the amount of water added to the system and maintaining the temperature at a constant $75^{\circ} \mathrm{C}$. It was found the amount of water absorbed onto the ceria coating increased with increasing partial pressure of water. A plot of this change in 
frequency or mass against the partial pressure resulted in a graph typical of a type II absorption isotherm (fig. 7(a)). Addition of further water to the already saturated system resulted in a linear increase in the mass of water detected on the crystal due to simple physical deposition. The BET equation (Eq. 1) can be used to calculate the enthalpy of absorption $\left(\Delta \mathrm{H}_{\mathrm{ads}}\right)$ and the volume of a monolayer of molecular water adsorbed onto a surface:

$$
1 /\left[V a\left(\frac{P_{0}}{p}-1\right)\right]=\left(\frac{C-1}{V_{M} C}\right)\left(\frac{P}{P_{0}}\right)+\frac{1}{V m C}-\text { Eq. } 1
$$

where $V_{m}$ is the volume of an adsorbed monolayer and $C=\exp \left(\Delta \mathrm{H}_{\text {ads }}-\Delta \mathrm{H}_{\text {liq }} / \mathrm{RT}\right)$. A plot of $P / V_{a}\left(P_{0}-P\right)$ versus $P / P_{0}$ yields a straight line, the slope of which is $(C-1) /\left(V_{M} C\right)$ and intercept is $1 / V_{m} C$. The BET plot for $\mathrm{H}_{2} \mathrm{O}$ adsorption produces a straight line, with $\mathrm{R}^{2}$ values of 0.995 (fig. 7).
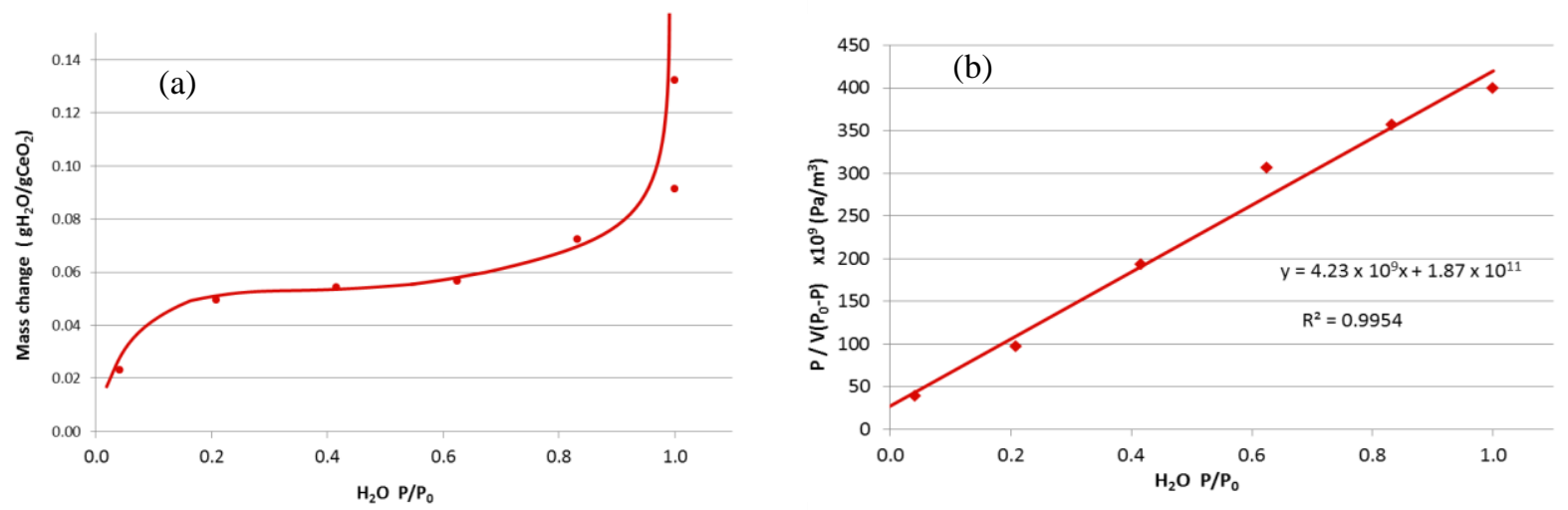

Figure 7. Graphs showing the a) change in mass of water with increasing partial pressure and b) the corresponding BET plot, with intercept $3.92 \times 10^{-9} \mathrm{~Pa}^{-3}$ and gradient $1.87 \times 10^{11} \mathrm{~Pa} \cdot \mathrm{m}^{-3}$.

The volume of an adsorbed monolayer of water on the $\mathrm{CeO}_{2}$ films was calculated to be $2.43 \times 10^{-13} \mathrm{~m}^{3}\left(1.35 \times 10^{-8} \mathrm{~m}^{3} \cdot \mathrm{g}^{-1} \mathrm{CeO}_{2}\right)$. Using an estimate for the footprint of a molecule of water of $1.60 \times 10^{-19} \mathrm{~m}^{2}$, this corresponds to an accessible surface area of $1.30 \times 10^{-3} \mathrm{~m}^{2}$ $\left(72 \mathrm{~m}^{2} \mathrm{~g}^{-1} \mathrm{CeO}_{2}\right)$. The mass of water absorbed at saturated humidity at $75^{\circ} \mathrm{C}$ corresponds to 7 monolayers of water. The $\Delta \mathrm{H}_{\text {ads }}$ for water adsorption can also be calculated: Taking the $\Delta \mathrm{H}_{\text {liq }}$ of water at $75^{\circ} \mathrm{C}$ to be $38.5 \mathrm{kJmol}^{-1}, \Delta \mathrm{H}_{\text {ads }}$ for $\mathrm{H}_{2} \mathrm{O}$ on $\mathrm{CeO}_{2}$ was calculated to be $-50.7 \mathrm{kJmol}^{-1}$. This value is within the range proposed by Paffett et al. for $\mathrm{H}_{2} \mathrm{O}$ adsorption on $\mathrm{PuO}_{2}$ of between -43 and $-51 \mathrm{kJmol}^{-1}$ [9], which suggests that molecular water adsorbed on $\mathrm{CeO}_{2}$ is bound by a similar mechanism as on $\mathrm{PuO}_{2}$.

\section{CONCLUSIONS}

We have developed a QCM based method for measuring water adsorption on $\mathrm{CeO}_{2}$, in closed conditions. In our system, an $o-\mathrm{GaPO}_{4}$ crystal is coated on one face with a voided $\mathrm{CeO}_{2}$ film. Water adsorption on $\mathrm{CeO}_{2}$ was measured by introducing various amounts of water into the vessel at $75^{\circ} \mathrm{C}$, resulting in a range of humidities up to the saturation vapour pressure. It was found that up to $2.4 \mathrm{mg}$ of $\mathrm{H}_{2} \mathrm{O}$ adsorbs on the $\mathrm{CeO}_{2}$ film at $75^{\circ} \mathrm{C}$ and $100 \%$ relative humidity, equivalent to 7 monolayers of water adsorbed over the top surface of the $\mathrm{CeO}_{2}$ layer. This is within the range of monolayers of water reported to adsorb on $\mathrm{PuO}_{2}$ powders [10, 14], suggesting a similar mechanism for $\mathrm{CeO}_{2}$ binding of water. We have determined the enthalpy of 
absorption of water onto $\mathrm{CeO}_{2}$ to be $-50.7 \mathrm{kJmol}^{-1}$ at $75^{\circ} \mathrm{C}, 12 \mathrm{kJmol}^{-1}$ greater than the enthalpy of evaporation. This enthalpy is within the range predicted for the absorption of water onto $\mathrm{PuO}_{2}$, indicating this method allows for investigation of water absorption using microgram samples. Work continues to study the absorption of water onto $\mathrm{CeO}_{2}$ at higher temperatures to discover the point at which all water is desorbed. Plans are also currently underway to apply this method directly to $\mathrm{PuO}_{2}$ waste samples.

\section{ACKNOWLEDGMENTS}

The authors would like to acknowledge the EPSRC (Award No. EP/L014041/1), The National Nuclear Laboratory and Nuclear Decommissioning Authority (Agreement No. 1006049) and the Lloyd's Register Foundation (LRF) for funding. LRF supports the advancement of engineering-related education, and funds research and development that enhances safety of life at sea, on land and in the air.

\section{REFERENCES}

[1] I. A. E. Agency, Annual Report for: International Atomic Energy Agency., 1998.

[2] J. L. Stakebake, J. McClard, and R. W. Szempruch, "Stabilization and packaging of plutonium oxide for 50-year storage.," Abstracts of Papers of the American Chemical Society, vol. 219, pp. U70-U70, Mar 26 2000.

[3] N. C. Hyatt, "Plutonium management policy in the United Kingdom: The need for a dual track strategy," Energy Policy.

[4] H. S. Kim, C. Y. Joung, B. H. Lee, J. Y. Oh, Y. H. Koo, and P. Heimgartner, "Applicability of $\mathrm{CeO} 2$ as a surrogate for $\mathrm{PuO}_{2}$ in a MOX fuel development," J. Nucl. Mater., vol. 378, pp. 98-104, // 2008.

[5] N. Sakai, K. Yamaji, T. Horita, H. Yokokawa, Y. Hirata, S. Sameshima, et al., "Determination of hydrogen solubility in oxide ceramics by using SIMS analyses," Solid State lonics, vol. 125, pp. 325-331, 10// 1999.

[6] M. Prin, M. Pijolat, M. Soustelle, and O. Touret, "Characterization of a Cerium Dioxide Powder from Its Equilibrium with Water-Vapor," Thermochimica Acta, vol. 186, pp. 273-283, Sep 251991.

[7] J. L. Stakebake, "Thermal Desorption Study of Surface Interactions between Water and Plutonium Dioxide," Journal of Physical Chemistry, vol. 77, pp. 581-586, 1973.

[8] J. L. Stakebake and L. M. Steward, "Water Vapor Adsorption on Plutonium Dioxide," Journal of Colloid and Interface Science, vol. 42, pp. 328-333, 1973.

[9] M. T. Paffett, D. Kelly, S. A. Joyce, J. Morris, and K. Veirs, "A critical examination of the thermodynamics of water adsorption on actinide oxide surfaces," Journal of Nuclear Materials, vol. 322, pp. 45-56, Oct 12003.

[10] J. M. Haschke, T. H. Allen, and J. L. Stakebake, "Reaction kinetics of plutonium with oxygen, water and humid air: Moisture enhancement of the corrosion rate," Journal of Alloys and Compounds, vol. 243, pp. 23-35, Oct 151996.

[11] P. Murphy, C. Boxall, R. Taylor, and D. Woodhead, "Investigation of water adsorption on metal oxide surfaces under conditions representative of $\mathrm{PuO} 2$ storage containers," ECS Trans., vol. 53, pp. 81-94, 14 pp., // 2013.

[12] C. T. Nottbohm and C. Hess, "Investigation of ceria by combined Raman, UV-vis and X-ray photoelectron spectroscopy," Catalysis Communications, vol. 22, pp. 39-42, 5/10/ 2012.

[13] P. Patnaik, Handbook of Inorganic Chemicals: McGraw-Hill, 2003.

[14] S. Hayun, T. Y. Shvareva, and A. Navrotsky, "Nanoceria - energetics of surfaces, interfaces and water adsorption," J. Am. Ceram. Soc., vol. 94, pp. 3992-3999, // 2011. 